\title{
SINERGIA
}

REVISTA DO INSTITUTO DE CIÊNCIAS ECONÔMICAS, ADMINISTRATIVAS E CONTÁBEIS (ICEAC)

\section{FLUXO DE SERVIÇO PARA MAPEAR FALHAS: ESTUDO NO SETOR DE CONSTRUÇÃO DE PLATAFORMAS PETROLEIRAS}

\author{
LUIZ ALEXANDRE SOUZA COIMBRA \\ ERROL FERNANDO ZEPKA PEREIRA JÚNIOR* \\ LÍVIA CASTRO D'ÁVILA* \\ ELIZA ANTONINI SCHROEDER
}

\section{RESUMO}

O presente estudo trata-se de uma abordagem que busca identificar, desenhar, medir, monitorar, controlar e melhorar os processos de negócio nas organizações que trabalham ou prestam serviços Aduaneiros e Logísticos para a construção de Plataformas Petrolíferas. A ideia é alinhar os processos de negócio à estratégia da organização, para que ela obtenha o desempenho desejado. Este trabalho aborda questões sobre identificação de falhas, problemas, execução, fluxograma e mapeamento de processo, de forma a monitorar, documentar e controlar o fluxo aduaneiro de importação. Para isso, foi feito um trabalho de "proposição de planos", de cunho qualitativo, a saber: estudo de caso. Os dados foram coletados por meio de observação participante, entrevistas e conversa do cotidiano, na Cidade do Rio Grande no Rio Grande do Sul, no período de março a junho de 2017. Os dados coletados foram organizados, preparados e analisados, desde a transcrição das entrevistas em arquivo pdf até as notas de observação, notas das conversas do cotidiano digitalizadas, áudios e vídeos arquivados. Como principais resultados, encontraram-se falhas entre os fornecedores, os clientes e o próprio prestador do serviço, nestes, destacam-se: (i) demora na análise documental; (ii) falta de um banco de dados com descrições de materiais já cadastrados anteriormente; (iii) erros de registro por falta de comunicação e compreensão da utilidade da planilha de registro; (iv) valor cobrado pela prestação de serviço não condiz com que é vendido; (v) a percepção do cliente quanto aos usos internos das ferramentas pelo prestador de serviço; (vi) falta de esclarecimento e base legal de assuntos como consultoria; e (vii) falta de proatividade e atraso nos registros.

Palavras-chave: Mapeamento de processos; Fluxograma; Identificação de falhas.

\section{ABSTRACT}

The present study is an approach that seeks to identify, design, measure, monitor, control and improve business processes in organizations that work or provide Customs and Logistics services for the construction of Oil Platforms. The idea is to align business processes with the organization's strategy so that it achieves the desired performance. This work addresses questions about fault identification, problems, execution, flowchart and process mapping, in order to monitor, document and control the flow of import customs. For this, a paper "proposal of plans" was done, of qualitative character, namely: case study. Data were collected through participant observation, interviews and daily conversation, in Rio Grande City, Rio Grande do Sul, from March to June 2017. The data collected were organized, prepared and analyzed, from the transcription of interviews in pdf file, as well as the notes of observation, notes of the daily conversations digitized, audios and videos archived. The main results were found to be flaws between suppliers, customers and the service provider. These include: (i) delay in documentary analysis; (ii) lack of a database with descriptions of materials previously registered; (iii) registration errors due to lack of communication and understanding of the usefulness of the registration worksheet; (iv) value charged for the rendering of service does not match what is sold; (v) the customer's perception of the internal uses of the tools by the service provider; (vi) lack of clarification and legal basis for matters such as consulting; and (vii) lack of proactivity and record delays.

Keywords: Process mapping, Flowchart, Fault identification.

Recebido em: 20-01-2019 Aceito em: 05-06-2019

\footnotetext{
*Bacharel em Administração pela Universidade Federal do Rio Grande. E-mail: alexandrecoimbra@hotmail.com.br Mestrando em Administração pela Universidade Federal do Rio Grande. MBA em Gestão estratégica de Negócios, pela Universidade Norte do Paraná. Bacharel em Administração pela Universidade Federal do Rio Grande.

Doutora em Administração pela Universidade do Vale do Rio dos Sinos. Mestra em Administração pela Universidade do Vale do Rio dos Sinos. Graduada em Administração pela Universidade Federal do Rio Grande.

Graduada em Gestão Hospitalar e Saúde - Faculdades Atlântico Sul de Rio Grande. Graduada em Administração - Universidade Federal do Rio Grande.
} 


\section{INTRODUÇÃO}

A necessidade de importação para construção de plataformas no contexto do Polo Naval do Rio Grande envolve toda uma estrutura de processos e pessoas, tanto no recebimento como na entrega de produtos e serviços.

Nesse contexto, estão as atividades de despacho aduaneiro pertinentes às liberações de importações e exportações de materiais, muito importantes para o desenvolvimento da construção de plataformas petroleiras, denominadas FPSO. Atividades essas, relativas aos processos de importação, exportação, consultoria e liberação das mercadorias junto à Receita Federal, que dependem da figura importante do despachante aduaneiro que, geralmente, são empresas prestadoras de serviço que contam com a representação legal nomeada pelo Importador junto à Receita Federal. Dessa forma, o prestador pode operar o despacho aduaneiro através do Sistema Integrado do Comercio Exterior - SISCOMEX. Esse sistema, segundo o site da Receita Federal (2016), é um instrumento administrativo que integra as atividades de registro, acompanhamento e controle das operações de comércio exterior, conforme 0 Decreto no 660, de 25 de setembro de 1992.

Os registros de importações representam a atividade com maior volume para a prestadora de serviços, aumentando o grau de responsabilidade e envolvimento no processo de comércio exterior da empresa contratante. Além disso, cabe ressaltar que essas importações para construção de Plataformas Petroleiras têm o incentivo do Governo Federal de suspensão dos impostos estaduais e federais: ICMS, II, IPI, PIS e CONFINS. Esse incentivo é dado pela Instrução Normativa 513, de 17 de fevereiro de 2005, por meio do Ato Declaratório, autorizado e publicado em Diário Oficial da União, pela Delegacia da Superintendência da Alfândega do Rio Grande, na qual a suspensão desses se dará como isenta, mediante a exportação da plataforma acabada. Registros internos da empresa estaleiro revelam que, somente na importação do casco em 2016, foram suspensos em torno de $\mathrm{R} \$ 500.000 .000,00$ em impostos.

O processo de comércio exterior envolve desde a compra de produtos até o registro das declarações de importação. Nele, há diferentes possibilidades de erros e falhas que devem ser evitados, pois podem gerar multas ou, até mesmo, perda do regime. Como referem Zeithaml et al. (2014), as ocorrências de divergências ou discrepâncias na entrega do serviço podem gerar problemas para o cliente ou para 0 prestador de serviço. Os clientes que têm problemas com a prestação de serviço podem ter a sua percepção da qualidade afetada.

A "Despachante ALX" presta serviços de despachos e consultoria à empresa contratante e cliente, o "Estaleiro BZH" (Cabe destacar que esses nomes atribuídos às empresas são fictícios e serão usados, ao longo do trabalho, como forma de preservar os nomes reais das empresas.). Nesse contexto, perceberam-se alguns erros na operação que não são evitados, tais como: falha na conferência de documentos, dificuldades com descrições de mercadorias e erro no lançamento de dados no sistema.

A prestadora de serviço tem como desafio gerencial evitar ou eliminar possíveis falhas ou lacunas no processo de importação de forma a evitar a insatisfação do cliente. Dessa forma, este artigo tem por objetivo elaborar o fluxo de serviço de forma a evitar falhas no processo de importação da prestação de serviços aduaneiros desenvolvido pela Despachante ALX. Como forma de alcançar tal objetivo, definiram-se os seguintes objetivos específicos: identificar as falhas no processo de importação por meio das experiências dos profissionais do cliente; mapear o processo de importação da empresa "Estaleiro BZH"; elaborar o fluxo de processo de importação, destacando os pontos de falha; e sugerindo ações para a melhoria de procedimentos.

A justificativa do trabalho pode ser demonstrada pela sua contribuição empírica, por obter informações para melhorar o fluxo de importação de materiais e equipamentos para construção do caso analisado, auxiliando na tomada de decisão para a eliminação de falhas no serviço de importação.

Este artigo está estruturado da seguinte maneira: além da introdução, a segunda seção compreende o referencial teórico: das falhas no processo de serviço à eliminação das divergências; o mapeamento de processos; e, ainda, a aplicação do fluxograma de serviços. Logo após, descrevem-se os procedimentos metodológicos empregados neste estudo, após, apresentam-se os resultados e, na última seção, fazem-se as considerações finais.

\section{FALHAS NO PROCESSO DE SERVIÇO}

Os serviços são avaliados por meio do uso de critérios de desempenho e, também, por meio de dimensões de qualidade, por serem intangíveis e envolverem uma experiência incomum com o cliente (BARROS e OLIVEIRA, 2014). Segundo Villamizar, Ramirez e Rodriguez (2013), o desempenho de qualquer serviço é resultado de uma combinação entre diversos fatores, como o local onde o serviço é prestado, as instalações onde ocorrem o serviço, os equipamentos e materiais utilizados durante a prestação do serviço e o responsável ou a equipe de pessoas que executaram o serviço. Ainda para os 
autores, a avaliação da qualidade do serviço é algo que depende de vários fatores, em sua maioria subjetivos, tais como, a percepção dos clientes, sua expectativa quanto ao resultado, a experiência deste com relação a serviços anteriores e a urgência das suas necessidades naquele momento.

Nesse sentido, Zacharias, Figueiredo e de Almeida (2008) explicam que, quando a prestação do serviço acontece em conjunto da presença do cliente, a questão da qualidade pode ter novas variáveis que permitem o seu melhor gerenciamento, pois o cliente pode opinar acerca de suas vontades, o que pode tornar mais próxima a resposta a suas solicitações e recomendações. Os autores seguem sua explicação ao mostrar o contraponto. Todavia, isso pode, também, ser um problema, pois o serviço torna-se mais complexo de ser executado, uma vez que a presença do consumidor pode dificultar sua execução.

$\mathrm{He}$, Aggarwal e Nof (2018) explicam que, naqueles serviços que ocorrem sem o contato direto com o cliente e são totalmente automatizados, a qualidade dos serviços torna-se mais simples, porque obedece a procedimentos e a operações padronizadas, e não a variações nas opiniões no momento de sua execução. Os autores, porém, ressaltam que o tipo ou a característica do serviço, além de serem o guia para a sua execução, devem focar na satisfação do cliente acima de tudo, pois os serviços acontecem em um clima de grande incerteza, expectativa do cliente, e, muitas vezes, desconhecimento deste por parte da empresa que presta o serviço, o que pode gerar falhas em sua execução.

A falha de serviço para Lovelocke Wright (1995) é definida como "uma percepção dos clientes de que um ou mais aspectos específicos da entrega do serviço não atenderam suas expectativas". Baseado em Johnston e Clarck (2014), registra-se que os tipos de falhas do serviço se caracterizam por $20 \%$ de falhas do próprio serviço, $27 \%$ de falhas dos bens/equipamentos/instalação e $53 \%$ de falhas do próprio cliente. Ainda para os autores, os erros que podem ser cometidos por clientes são, frequentemente, não intencionais.

Entretanto, a qualidade dos serviços, à luz de Fitzsimmons e Fitzsimmons (2014), é a relação entre as expectativas prévias dos clientes e suas percepções durante e após a respectiva prestação do serviço. Já para Lovelock (1993), a qualidade do atendimento é equiparada com a satisfação do cliente e, a partir desse conceito, é possível identificar falhas que podem levar ao desapontamento do cliente. Proposição semelhante a essa é a de Zeithaml et al. (2014), que aponta as principais causas de falhas na qualidade de serviço, os GAPs, ou seja, são capazes de ser percebidos pelo cliente através das discrepâncias entre expectativa e percepção.

Para os clientes, avaliar a qualidade em serviços é mais difícil do que avaliar a qualidade de bens tangíveis. Uma forma de avaliação e medida da qualidade do serviço esperado, e ou percebido, está na identificação das lacunas ou GAPs da qualidade (Fitzsimmons e Fitzsimmons, 2014). Conforme Martins e Laugeni (2009), um serviço apresenta elementos de qualidade, e é preciso identificar e eliminar as divergências que existem dentro da empresa e entre a empresa e o cliente, das quais resulta baixa qualidade de serviço.

A avaliação das divergências entre o serviço esperado e o percebido é um processo rotineiro de retorno de informação do cliente, praticado pelas principais empresas de serviços (Fitzsimmons e Fitzsimmons, 2014). Para isso, o retorno do cliente é importante para sinalizar e identificar as falhas no processo e, de acordo com Johnston e Clark (2014), o mapeamento do processo é uma ferramenta útil no processo de identificação que será apresentado a seguir.

\section{MAPEAMENTO DE PROCESSOS}

A ciência da administração nasceu da necessidade de adequação de tarefas aos métodos e processos de trabalho, em que essa busca por eficiência, por intermédio das melhores maneiras de fazer o trabalho modelaram a administração das primeiras décadas do século vinte (Pereira Junior, Longaray e Munhoz, 2017). Conforme explicam os autores, esta busca por esta racionalização do trabalho no nível operacional levou o engenheiro Frederick Taylor a ser o pioneiro em assumir uma atitude metódica de analisar e organizar o trabalho da base até o topo da organização. Nesse sentido, Certo (1994) explica que as críticas à teoria clássica da administração são fundamentais à discussão, todavia, o princípio deixado por Taylor delineia a ciência administrativa ainda um século depois: como alcançar objetivos pelo trabalho por intermédio de pessoas e recursos organizacionais disponíveis.

Historicamente, a ênfase nos processos empresariais em resposta à busca pela melhoria do desempenho organizacional origina-se na década de 70 , quando os modelos japoneses de qualidade começam a ser adotados pelo resto do mundo (Moreno e Santos 2012). Muitos são os trabalhos encontrados na literatura acerca de mapeamento de processos, de suas técnicas e de implicações. Todavia, torna-se relevante apresentar o trabalho de Longaray et al. (2018), em que os autores apresentam a caracterização da produção científica sobre o mapeamento de processos publicados entre 2006 e 2016 , por meio de uma análise de artigos disponíveis em bases de dados online e da bibliometria na realização do estudo da produção, da autoria, do conteúdo e das referências bibliográficas dos artigos selecionados. Entre os principais resultados neste estudo, destaca-se que o tema mais abordado nos artigos foi a 
efetividade das equipes de processo. A maioria dos artigos analisados foi escrita por 2 ou 3 autores. Quanto aos autores mais produtivos, pode-se destacar: Bossche, P. V. D.; Day, D. V.; Gabelica, C.; Gijselaers, W.; Gilson, L. L; Mathieu, J. E; Maynard, M. T.; e Segers, M. Já as universidades que mais se destacaram em termos de produção científica sobre o tema foram: Maastricht University (Netherlands), University of Antwerp (Belgium) e University of Connecticut (USA).

Com relação à conceituação do termo mapeamento de processos, pode-se apresentar as discussões baseadas em Lovelock (1995), em que o autor explica que o aprimoramento da qualidade requer a identificação de causas específicas de cada falha e a tomada de ações estratégicas de desenvolvimento para saná-las. Dando sequência ao assunto, Pinho et al. (2006) explicam que ter uma visão do processo permite identificar as falhas, uma vez que o entendimento do desencadeamento das atividades do processo dá à empresa uma compreensão mais clara das tarefas executadas no negócio.

À luz de Fitzsimmons e Fitzsimmons (2014), esquematizar um processo, identificar a operação e determinar a capacidade do sistema é fundamental no gerenciamento de operações de serviços. As formas de processos produtivos, indiferente do tipo de falha, são de grande importância para que os produtos ou serviços não falhem, pois podem gerar altos prejuízos (Slack et al., 2002).

O processo permite a identificação e a visualização da operação de determinadas tarefas, pois, conforme Lovelock (1995), o mapeamento do processo serve como a ferramenta para dar suporte para uma visão mais ampla. De acordo com Johnston e Clark (2014), o mapeamento do processo é uma ferramenta útil, porque tenta sinalizar onde estão os problemas. Além disso, Pereira Junior et al. (2018) acrescentam que a gestão, através dos processos mapeados, gera vários benefícios, a saber: satisfação dos clientes, redução de custos e preços dos produtos e serviços, inovação dos produtos, aumento das receitas, melhorias na lucratividade e aumento percentual da participação de mercado.

Cheung e Bal (1998) definem o mapeamento de processos como a técnica de se colocar em um diagrama o processo de um setor, de um departamento ou de uma organização, para orientação em suas fases de avaliação, desenho e desenvolvimento. O mapeamento de processo é a forma de visualizar o processo de serviço de forma a orientar suas fases de avaliação e desenvolvimento (Johnston e Clark, 2014).

\section{FLUXOGRAMA DE SERVIÇO}

Nos fluxogramas, de acordo com Fitzsimmons e Fitzsimmons (2014), podem ser representados os processos para auxiliar os membros da equipe a identificar possíveis problemas ou pontos para soluções. Além disso, um fluxograma possibilita visualizar as principais falhas no processo de serviço; uma das técnicas para identificar possíveis falhas é o uso do service blueprint. Go e Kim (2018) explicam que o service blueprint vem a ser uma ferramenta desenvolvida originalmente por Shostack (1984), a fim de mapear processos de serviços, diferenciando as atividades de linha de frente e as atividades da retaguarda, representando graficamente. A sequência do processo é um tipo de fluxograma, todavia o seu diferencial é permitir a melhor visualização das atividades que envolvem a participação dos clientes.

Longaray et al. (2018) explicam que, entre as várias abordagens de metodologias para se fazer o mapeamento de processos de negócio que surgiram no início década de 90, as que ganharam destaque foram as que condicionavam o desenho dos processos a estratégias organizacionais. Ainda para os autores, a partir de 1995, com o advento da popularização do uso da internet como ferramenta gerencial, abordagens mais específicas começaram a surgir, a fim de integrar a empresa em seus elos na sua cadeia de suprimentos. Moreno e Santos (2012) acrescentam que, recentemente, utilizando-se a tecnologia da informação como ferramenta de suporte, a fim de integrar os processos do negócio, as pessoas e o conhecimento mais efetivo nos processos da organização, surge o Business Process Management - BPM.

Segundo Benedete Junior (2007), a utilização do BPM (Business Process Management), nos negócios da empresa, possibilita contribuir em mapear e melhorar os processos, através da modelagem, execução, monitoramento e análise dos processos de negócio. Netto (2008) afirma que uma organização consegue coordenar o ciclo completo dos processos de seu negócio e visualizar as ligações entre pessoas, tecnologias e processos propriamente ditos.

De maneira específica, o service blueprint é a representação esquemática e detalhada de todas as etapas do processo de entrega de um serviço, identificando tanto as atividades de linha de frente como as atividades de retaguarda, separadas pela denominada linha de visibilidade (FITZSIMMONS e FITZSIMMONS, 2004). A fim de elucidar, apresenta-se, na figura 1, o exemplo de uma análise, utilizando o service blueprint em um processo de entregas de refeições, baseado no trabalho de Santana, Borges e Borges (2011). 
FIGURA 1 - Análise utilizando o service blueprint em um processo de entregas de refeições

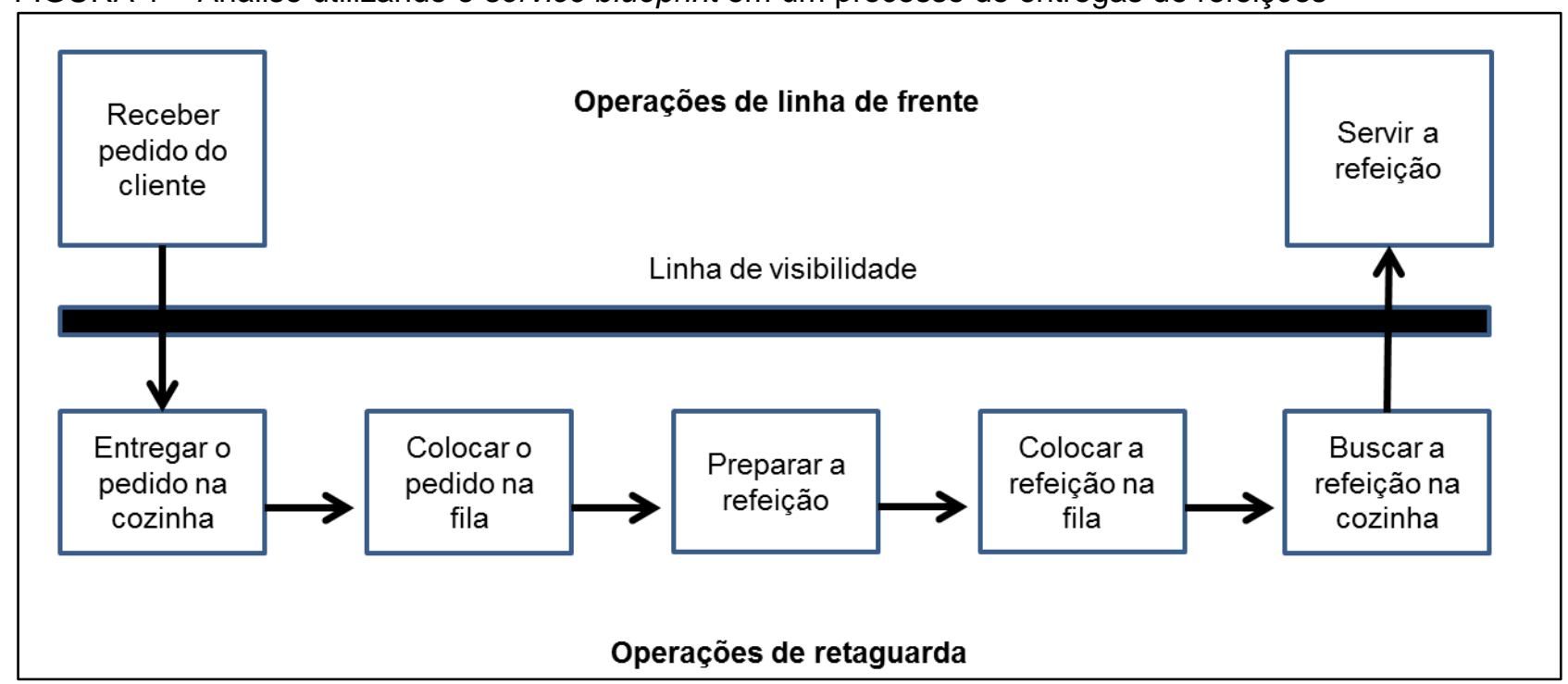

FONTE: Santana, Borges e Borges (2011).

Para entender melhor o conceito do BPM, apresenta-se, a seguir, o quadro 1, em que estão detalhadas as informações sobre cada elemento de notação que contém um desenho de modelagem de processo.

QUADRO 1 - Elementos de Notação

\begin{tabular}{|c|c|c|}
\hline Nomes & Notações & Descrições \\
\hline Início & & $\begin{array}{c}\text { Usual para início de processo, quando não incorrer } \\
\text { em nenhum dos tipos anteriores. }\end{array}$ \\
\hline Atividades & & $\begin{array}{l}\text { É o tipo genérico de atividade, normalmente utilizado } \\
\text { nos estágios iniciais do desenvolvimento do processo. }\end{array}$ \\
\hline Subprocessos & 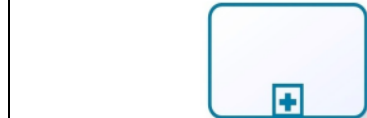 & $\begin{array}{l}\text { Quando uma atividade contém outras atividades, o } \\
\text { subprocesso é dependente do processo, mas possui } \\
\text { fluxo próprio. }\end{array}$ \\
\hline Gateways & & $\begin{array}{l}\text { Para esse gateway, existe uma decisão e somente um } \\
\text { dos caminhos pode ser escolhido. Um dos caminhos } \\
\text { deve ser o padrão, sendo ele o último a ser considerado. }\end{array}$ \\
\hline Gateways & & $\begin{array}{l}\text { Gateway paralelo: utilizado quando não há decisão a ser } \\
\text { tomada, todos os caminhos devem ser seguidos } \\
\text { simultaneamente. Quando for necessário sincronizar os } \\
\text { fluxos, utiliza-se o mesmo gateway. }\end{array}$ \\
\hline $\begin{array}{l}\text { Objetos de } \\
\text { conexão }\end{array}$ & & $\begin{array}{l}\text { Fluxo de Sequência: usado para mostrar a ordem em } \\
\text { que as atividades são processadas. }\end{array}$ \\
\hline Eventos Fins & & $\begin{array}{l}\text { Tipo Nenhum: usual para finalizar o processo, quando } \\
\text { não incorrer em nenhum dos tipos anteriores. }\end{array}$ \\
\hline Sinal & & $\begin{array}{l}\text { Mostra como alerta nas atividades com potencial falha e } \\
\text { um sinal será enviado a um ou mais eventos. }\end{array}$ \\
\hline Piscina & & $\begin{array}{l}\text { Representa um participante dentro do processo, } \\
\text { podendo atuar como uma raia para separar um conjunto } \\
\text { de atividades de outra Piscina. }\end{array}$ \\
\hline Raia & & $\begin{array}{l}\text { É uma subpartição dentro de uma Piscina de forma } \\
\text { Horizontal ou vertical. Também são usadas para } \\
\text { organizar e categorizar as atividades, contribuindo para } \\
\text { seu aumento. }\end{array}$ \\
\hline
\end{tabular}

FONTE: elaborado pelos autores (2019). 


\section{MÉTODO DA PESQUISA}

Quanto ao propósito desta pesquisa, a mesma é uma proposição de planos. Para Martins e Theóphilo (2009), a proposição de planos e programas trata-se de uma estratégia de pesquisa que apresenta soluções para problemas organizacionais já diagnosticados, buscando, por meio de uma pesquisa empírico-analítica, um estudo de viabilidade de planos alternativos para a solução de problemas, propondo a aplicação de modelos a situações práticas, sendo valorizadas a engenhosidade e a criatividade quanto às adaptações do modelo teórico a uma situação específica.

Quanto à abordagem, este artigo pode ser classificado como qualitativo. Flick (2009) explica que a pesquisa qualitativa visa entender, descrever e explicar os fenômenos sociais de modos diferentes, por meio da análise de experiências individuais e grupais, do exame de interações e das comunicações que estejam se desenvolvendo, assim como da investigação de documentos (textos, imagens, filmes ou músicas) ou dos traços semelhantes de experiências e integrações. Para Severino (2017), a pesquisa qualitativa pode ser definida como um conjunto de diferentes técnicas interpretativas, em que se procura descrever e decodificar os componentes em que há um sistema complexo com muitos significados, tendo por objetivo traduzir e expressar o sentido dos fenômenos do mundo social para o pesquisado.

Quanto ao seu método, este trabalho é um estudo de caso. Yin (2015) define estudo de caso como sendo um estudo que tem por objetivo investigar um fenômeno contemporâneo em profundidade e em seu contexto de vida real, especialmente quando os limites entre o fenômeno e o contexto não têm uma evidência tão clara de ser percebida. A vantagem do estudo de caso é que ele permite concentrar-se em situações da vida real e avaliar perspectivas relacionadas ao fenômeno à medida que ele se desenvolve na prática (Flyvbjerg, 2006). O pesquisador buscou compreender em profundidade a atividade de importação, descrevendo problemas de falhas no processo aduaneiro. Procurou envolver múltiplas fontes de informações para relatar e delimitar o caso dentro do local de estudo. Somado a isso, o pesquisador, por ser funcionário da empresa prestadora de serviço, teve livre acesso às dependências do "Estaleiro BZH" e envolvimento com as experiências reais dos participantes.

Acessoriamente à investigação, caracteriza-se como pesquisa participante. A observação participante, fundamentado em descobertas no campo, envolve a participação do pesquisador no dia a dia dos pesquisados. Por isso, a observação participante deve ser personalizada e multifatorial, requerendo um compromisso de longo prazo. As suas principais características são a ênfase na análise da natureza de um fenômeno social específico, o trabalho com dados qualitativos sem ter um esquema de análise de categorias previamente fixado e a análise de dados que envolvem interpretações explícitas dos significados das ações humanas. Os resultados são obtidos de modo indutivo e dialógico, ou seja, as conclusões podem ser discutidas com os informantes à medida que a observação se desenrola e as interpretações vão sendo construídas pelo pesquisador (ABIB, HOPPEN e HAYASH JUNIOR, 2013). Tendo em vista a relação de trabalho do autor desta pesquisa com a empresa Despachante, determina-se proximidade entre 0 pesquisador e os atores do processo investigado- ambos se envolveram na análise de sua própria realidade de trabalho (GIL, 2002). Essas são descritas na sequência do método e serviram de base para conceber o mapeamento do processo e, posteriormente, o fluxo de importação.

Com isso, cabe destacar a conexão do pesquisador com o objeto de estudo, e os participantes da pesquisa que são os funcionários do "Estaleiro BZH". O ambiente de estudo se constitui no trabalho do pesquisador, caracterizando como uma pesquisa "no quintal". Por esse motivo, a coleta de dados pode ser conveniente e fácil, mas também pode tolher a capacidade do pesquisador em revelar informações e levantar questões difíceis de poder. Além disso, pode fazer com que os dados se tornem viesados, incompletos ou comprometidos (CRESWELL, 2007). Para evitar esse problema, o pesquisador deve empregar estratégias múltiplas de exatidão para criar confiança no leitor em relação à validação dos resultados (CRESWELL, 2007). Isto é, adotar mais de uma técnica de procedimento de coleta. Nesse sentido, optou-se por adotar as seguintes técnicas de coleta de dados: entrevista, observação, documentos e conversa do cotidiano. No entanto, para realizar os procedimentos, foi solicitado aos responsáveis dos setores de suprimentos e logística autorização informal e verbal para realizar o estudo no local. E que por questões éticas e privativas foi apresentado e assinado o termo livre, esclarecido de autorização para gravação dos áudios das entrevistas individuais dos participantes. Para Roesch et al. (2015), a técnica da entrevista objetiva entender o significado que os entrevistados atribuem a questões e situações em contextos que não foram estruturados anteriormente a partir das suposições do pesquisador.

Os atores participantes que foram propositalmente selecionados são os próprios funcionários do "Estaleiro BZH", dos setores Suprimentos, Logística, Fiscal e Comex e estão diretamente associados ao processo de importação. São eles: um comprador, um coordenador de logística, um analista fiscal, dois assistentes de informação. O pesquisador conduziu as entrevistas face a face com os funcionários, envolvendo poucas perguntas não-estruturadas e abertas, pretendendo extrair percepções e opiniões dos participantes a respeito do fluxo de processos de importação e da prestação de serviço aduaneiro. Destaca-se 
que o pesquisador, por ser funcionário do prestador serviço e de trabalhar diretamente com os atores do estaleiro, também contribuiu com o conhecimento e domínio dos objetivos do estudo. Além disso, o pesquisador, por ter intimidade com os atores, pode manter uma livre troca de informações, porém a dificuldade foi que alguns dos entrevistados não têm a visão de todo o processo de importação.

O registro das entrevistas foi feito por gravação de áudio e de vídeo, como forma de garantir as informações obtidas, caso algum dos equipamentos dessem problema, sendo que, na entrevista da analista fiscal, se perdeu o vídeo, mas pode salvar o áudio. Para a realização das entrevistas, elaborou-se um protocolo de entrevista com perguntas abertas e reflexivas para auxiliar o pesquisador a obter informações relevantes para o trabalho. Esse consta no apêndice deste trabalho. A observação é uma ferramenta para a coleta que consiste em observar um fenômeno no contexto do campo por meio dos sentidos da visão e audição do observador, por meio de um instrumento para registro (CRESWELL, 2014). Podendo observar o ambiente físico, as atividades, as interações e as conversas durante as observações no local de pesquisa caracterizando como perfil participante observador. Acessoriamente a isso, auxiliou para obter a visão e os dados subjetivos de quem está incluído na atividade. De acordo com Creswell (2014), entretanto, pode causar distração para o pesquisador registrar os dados quando ele está integrado à atividade.

O pesquisador registrou, de maneira não estruturada, as atividades de compra, logísticas, aduaneiras e fiscais no local. Tal condição possibilitou o registro de atividades, tarefas, procedimentos e informações à medida que elas foram reveladas. Entretanto, a desvantagem disso é que o pesquisador pode observar algumas informações privadas relacionadas ao cliente final do Estaleiro que não puderam ser relatadas no trabalho. Os sujeitos do Estaleiro BZH foram observados pelo pesquisador em horário de serviço, e as entrevistas transcorreram no mesmo período em momentos oportunos ou de intervalos.

A conversa do cotidiano também foi utilizada. De acordo com Menegon (2000), é um recurso que proporciona uma melhor interação social, ou seja, é uma fonte de informação que permite ao pesquisador estar em campo no momento do processo de pesquisa. Nesse contexto, as conversas informais viabilizaram a sustentação de ideias e descrições de como o processo deveria fluir de forma correta. Somado a isso, processos em tramitação real oportunizaram conversas que, para o pesquisador, foram relevantes para 0 estudo. As conversas do cotidiano foram registradas no caderno de observações quando algum assunto importante era discutido e considerado relevante para o estudo. No entanto, as principais dificuldades de adoção dessa técnica é que surgiram conversas no momento do trabalho profissional de maneira inesperada que acabaram dificultando o registro (SOUZA, 2005).

Como forma complementar para reunião de dados, buscou-se documentos, tais como: e-mails, faturas comerciais, registros de importação e ordens de compras. A vantagem dessa coleta foi poder acessar informações relativas da importação, como a ordem de compra, fatura comercial, packing list e conhecimento de embarque. Essas Informações foram de grande relevância para o estudo, permitiram não só a identificação das atividades realizadas, bem como as confirmações dos relatos sobre as falhas dos participantes.

$\mathrm{O}$ trabalho de campo foi realizado no escritório do Estaleiro $\mathrm{BZH}$, localizado na área portuária da Cidade do Rio Grande no Rio Grande do Sul, no período de março a junho de 2017. Não só os dados coletados foram organizados, preparados e analisados a partir da transcrição das entrevistas em arquivo pdf, bem como as notas de observação, as notas das conversas do cotidiano digitalizadas, os áudios e os vídeos arquivados. Dessa forma, para obter um significado geral das informações e refletir sobre seu sentido global, optou-se em organizar e preparar os dados, transcrevendo e digitalizando as notas escritas. Separaram-se as informações por assuntos mais relevantes para o trabalho, tais como: atores, profissão, setor, entrevistas transcritas, falhas do fornecedor, falhas do cliente, falhas do prestador, fluxo do processo de importação, observações e impactos. Dessa forma, o pesquisador pode extrair as informações relativas aos pontos de falhas, mapear o processo de serviço e elaborar fluxograma de importação e prover ações de recuperação do serviço.

\section{ANÁLISE DOS RESULTADOS}

Antes de descrever as falhas, detalha-se uma descrição de como o processo naturalmente acontece. O importador compra do fornecedor no exterior e, quando a mercadoria ou produto comprado chega ao Brasil, fica em recinto alfandegário, aguardando a liberação pela receita Federal. Assim que se tem esta liberação, com os tributos pagos, é o momento em que o importador emite a nota fiscal de entrada que será usada para transporte rodoviário do recinto até o armazém do importador. Entretanto, dentro desse contexto, têm-se os setores envolvidos para compra, logística, desembaraço e fiscal, para que seja realizada a importação e seu controle aduaneiro. Após descrever-se o processo, registram-se, aqui, as funções de cada um dos cinco entrevistados, representados por números, como de preservar identidades: (1) Comprador, (2) Coordenador de Logística, (3) Analista Fiscal, (4) Analista de Sistema, (5) Analista de Sistema/Logística. A seguir, descrevem-se as falhas decorrentes das ações do fornecedor, do cliente e do prestador segundo o entendimento dos funcionários cliente. 


\subsection{Falhas no fornecedor}

De acordo com as informações dos funcionários 1 e 2, do setor de suprimentos e logística, as primeiras falhas acontecem, justamente, no próprio fornecedor, tais como: divergência nas quantidades, material não declarado, divergência entre documentos e demora nas correções dos documentos. Por mais que sejam fornecedores indicados pelo cliente final do Estaleiro BZH e possuam experiências com outras plataformas, esses fornecedores cometem erros de divergência não só nas quantidades físicas como na documental, ou seja, produtos que chegam faltando ou produtos a mais que não foram declarados na Ordem de Compra e nem nos documentos instrutivos do despacho - Invoice, Packing List e Conhecimento de transporte.

Além disso, tem-se o relato pelos atores que a falha mais comum dos fornecedores é da Fatura Comercial não ser conforme a ordem de compra, primeiro e principal documento da negociação entre as partes. Isso causa perda de tempo com a análise documental, tanto do despachante como do setor fiscal do estaleiro. As discrepâncias ou divergências na fatura são retornadas para o fornecedor efetuar a correção dessa mercadoria comprada, em contrapartida, a solicitação dessas correções é muito demorada ou não é respondida. A consequência disso é a demora em coletar a carga na origem ou no registro da declaração de importação de forma errada ou nos despachos interrompidos pela Receita Federal, até que sejam retificadas as informações. Esse último gerando multas ou, até mesmo, pena de perdimento da mercadoria.

A falha no processo de compra se torna difícil à medida que as exigências, por conta da engenharia e planejamento, pressionam os compradores e a logística para acelerarem o processo da coleta e a entrega do produto. No entanto, existem fatores como a burocratização das barreiras alfandegárias entre países e a produção no fornecedor, que nem sempre os gestores do projeto levam em consideração ou tem conhecimento sobre.

\subsection{Falhas no cliente}

Analisando as informações levantadas durante a pesquisa, os atores apontaram falhas, também, no próprio procedimento de trabalho ou tarefas, isto é, os erros ou falhas nem sempre são por conta do fornecedor ou do prestador de serviço, e, sim, do próprio cliente, quando se trata por atividades manuais. Dentre essas falhas, destacam-se procedimentos manuais, falhas de comunicação e falha no cronograma estabelecido.

Relatou-se que as falhas comuns são as de procedimentos manuais como tarefas de emissão da ordem de compra no sistema interno, instrução para registro de forma errada, que acarreta erro na Declaração de Importação e erro na emissão da nota fiscal de entrada. Outras falhas de comunicação são: pedidos de compra muito em cima do prazo estipulado pela engenharia e planejamento, falhas de comunicação interna e com a prestadora de serviço e pedido para coleta de embarque antes da aprovação da análise documental. O mais relevante dentre fatores é a cobrança do setor de engenharia e planejamento para tentar cumprir com o cronograma estabelecido pelo cliente final, a Petrobras.Com base nesses dados, pode-se resumir que registros desses tipos de falhas no serviço de importação podem ser cometidos por clientes, mas que devem ser eliminadas e atendidas as retificações das questões aduaneiras por parte do Despachante.

\subsection{Falhas do prestador}

Nesta fase, os participantes relataram que o início do despachante no circuito está associado à análise documental da fatura comercial e packing list, sendo a fatura o primeiro documento a ser analisado, apontando as questões importantes para a realização do despacho. Entretanto, quando constam falta ou erro na fatura, o prestador repassa para o comprador, ou, em alguns casos, entra em contato direto com o fornecedor para solicitar as correções. Nessa fase, o cliente estaleiro pontuou o exagero de mensagens do prestador que acaba atrapalhando o andamento do processo de compra. Já o ator 3 relatou que, para diminuir essa comunicação, o despachante deveria consultar o histórico de outras entradas já realizadas no estaleiro. $\mathrm{O}$ argumento foi justamente de o despachante vender uma prestação de serviço em cima da experiência com outros estaleiros. Contudo, essas falhas poderiam ser evitadas ou eliminadas caso o prestador consultasse essas informações com antecedência.

Além disso, o processo de consulta aduaneira é complexo, determina muita informação para evitar transtornos como multa ou apreensão da carga pela Receita Federal. Mas, de fato, através de acompanhamento de e-mails e documentos, o pesquisador constatou relevância nesses casos apontados e entende que faltou uma gestão ou integração de todos os setores para compreensão do processo de importação como um todo.

Os atores, também, relataram os erros nos registros da DI e eram cometidos por conta de digitação da fatura comercial para o siscomex. Esses erros até hoje estão aguardando retificação por parte da Receita 
Federal, pois a mesma entende que retificações, como um ponto e vírgula ou parênteses (símbolos), não são prioridades para a alfândega. No entanto, a falta desses símbolos na $\mathrm{Dl}$ acaba não possibilitando a integração no sistema REPLAT de controle e de rastreamento do material para a Receita Federal. Para evitar isso, no decorrer do projeto, o pesquisador e o cliente conseguiram eliminar esses erros, por utilizar uma instrução de registro com base nas informações da fatura comercial e na ordem de compra.

Entre todos os atores entrevistados, a falha de maior impacto, tanto na obra como no financeiro, é a demora no registro da DI. O pesquisador constatou que muitos não foram registrados mediante a presença de carga e isso gerou desperdício com os custos de armazenagem em terminais portuários. Esses fatos foram apontados em processos que tiveram as análises documentais corretas e instrução para registro recebido em tempo hábil. Por isso, a importância de mapear e elaborar um fluxo do processo de importação para integrar as partes envolvidas para se ter um controle maior e agilidade no processo.

Das principais identificações de falhas extraídas que constam no quadro 2, pode-se analisar o tipo de falha que afeta a qualidade do serviço prestado. Portanto, para o cliente avaliar a qualidade da prestação de serviço, torna-se difícil, com isso, a identificação das falhas ou lacunas apresentam elementos de que é preciso eliminar dentro da empresa estaleiro e entre a empresa prestadora e o cliente, das quais resulta baixa qualidade de serviço.

QUADRO 2 - Falhas que afetam a qualidade do serviço

\begin{tabular}{|c|c|}
\hline Identificação & Falhas do Prestador \\
\hline Decessinição do gerenciamento dessas necessidades & $\begin{array}{c}\text { Falta de um banco de dados com descrições de } \\
\text { materiais já cadastrados anteriormente }\end{array}$ \\
\hline Compreensão das especificações do atendimento & $\begin{array}{c}\text { Erros de registro por falta de comunicação e } \\
\text { compreensão da utilidade da planilha de registro }\end{array}$ \\
\hline Propaganda e Promessas de vendas & $\begin{array}{c}\text { Valor cobrado pela prestação de serviço não condiz com } \\
\text { o que é vendido }\end{array}$ \\
\hline Execução das especificações do atendimento & $\begin{array}{c}\text { O cliente tem a percepção de que não seguem a planilha } \\
\text { de registro e, muito menos, consultam processos } \\
\text { anteriores com as mesmas características de produtos } \\
\text { Falta de esclarecimento e base legal de assuntos } \\
\text { como consultoria }\end{array}$ \\
\hline Interpretação que o cliente faz da comunicação & Falta de proatividade e atraso nos registros de DI \\
\hline
\end{tabular}
FONTE: dados da pesquisa.

\section{MAPEAMENTO DE PROCESSOS E ELABORAÇÃO DO FLUXO DE SERVIÇO}

No mapeamento do processo, estão os pontos de atividades e tarefas do processo de serviço de importação que seguem uma sequência lógica, iniciando com a solicitação de compra e terminando com a entrega na construção da plataforma. Apresenta-se, no quadro 3, todas as tarefas.

QUADRO 3 - Mapeamento do processo de importação

\begin{tabular}{|c|c|}
\hline № & Procedimento de atividades \\
\hline 1 & Requisitar o material para suprimentos pela engenharia e planejamento \\
\hline 2 & Iniciar o processo de compra e identificar os potenciais fornecedores que constam no vender list do cliente final \\
\hline 3 & Emitir a ordem de compra e a negociação com o fornecedor \\
\hline 4 & Encaminhar os documentos à Logística para providenciar a coleta no exterior \\
\hline 5 & Iniciar processo de análise documental entre despachante e setor fiscal coordenado pelo setor da logística \\
\hline 6 & Diligenciar e Inspecionar as condições da carga no fornecedor para o embarque e recebimento no estaleiro \\
\hline 7 & Providenciar a coleta do material e embarque pelo setor da Logística \\
\hline 8 & Providenciar o Despacho Aduaneiro da carga após sua chegada no país \\
\hline 9 & $\begin{array}{l}\text { Encaminhar o desembaraço da Declaração de Importação para emissão da Nota Fiscal de entrada e } \\
\text { transporte do porto de descarga até o Estaleiro }\end{array}$ \\
\hline 10 & Receber a carga estaleiro pelo almoxarifado \\
\hline 11 & Entregar o material liberado pelo almoxarifado para engenharia de execução da obra. \\
\hline 12 & Realizar o processo de industrialização e construção da Plataforma \\
\hline
\end{tabular}

FONTE: dados da pesquisa.

Apresenta-se, no quadro 4, a sequência do processo de importação com suas notações e simbologias, atividades representativas e portas de acesso. Seguem as descrições das principais atividades do Processo de Importação. 
QUADRO 4 - Processo de Importação

\begin{tabular}{|c|c|}
\hline Atividade & Descrição \\
\hline$E N G / P L A$ & $\begin{array}{l}\text { niciar o processo de solicitação da Engenharia e Planejamento para o setor de suprimento, por } \\
\text { neio de Requisição de Materiais que serão importados. Determinando ações como compra de } \\
\text { nateriais e equipamentos para construção e aplicação à plataforma. }\end{array}$ \\
\hline SUPRIMENTOS & $\begin{array}{l}\text { Receber o RM (criado no IFS e no SPMAT) da Engenharia e iniciar o processo de compra, que } \\
\text { consiste, primeiramente, na identificação dos potenciais fornecedores, respeitando o Vender List } \\
\text { do cliente final - Petrobras - para fechamento da compra. Após a identificação e o contato com } \\
\text { o fornecedor específico, a atividade em paralelo à compra é a abertura da Ordem de Compra no } \\
\text { sistema IFS, em que constam não só as características do material ou equipamento, bem como } \\
\text { as condições de pagamento da fatura em acordo. Nesse processo de receber a fatura - } \\
\text { INVOICE-, as informações contidas na Ordem de Compra devem ser as mesmas pertencentes } \\
\text { à Invoice. }\end{array}$ \\
\hline FORNECEDOR & $\begin{array}{l}\text { Receber o pedido de compra e iniciar o processo de negociação na forma de pagamento e } \\
\text { envio. Somente após a confirmação do pagamento, é que o fornecedor irá trabalhar no } \\
\text { processo de fabricação do item ou, caso tenha em estoque, irá disponibilizá-lo para coleta. } \\
\text { Neste momento da liberação do material, o fornecedor encaminha a Invoice para o comprador } \\
\text { verificar e analisar junto com o setor da logística. Nesse momento, é que a logística entra no } \\
\text { circuito e encaminha para a análise documental aduaneira para o despachante e para a análise } \\
\text { da ordem de compra para o fiscal da empresa compradora. }\end{array}$ \\
\hline LOGÍSTICA & $\begin{array}{l}\text { Efetuar a contratação do frete internacional assim que a documentação estiver OK. O setor } \\
\text { inicia o processo de coleta da carga após definir o Agenciador de Transporte. Considerando a } \\
\text { documentação OK e a carga pronta para coleta na origem, a Logística aguarda a autorização do } \\
\text { fornecedor para realizar a coleta para embarque no exterior. Logo em seguida, são } \\
\text { encaminhadas ao Despachante as previsões de coleta e chegada da carga para providência do } \\
\text { Desembaraço junto à Receita Federal, assim que confirmada a presença de carga no porto de } \\
\text { desembarque alfandegado. }\end{array}$ \\
\hline DESPACHO & $\begin{array}{l}\text { Inicia-se o processo de Despacho assim que recebida a instrução de registro do setor fiscal do } \\
\text { estaleiro. Com a documentação Original + instrução de registro, o despachante prepara as } \\
\text { atrativas de lançamento dos dados no Siscomex e aguarda a presença de carga para efetuar o } \\
\text { registro da Declaração de Importação - DI. Assim que chegada a carga no porto de } \\
\text { desembarque alfandegado e dado presença pelo terminal, o despacho é efetuado pelo registro } \\
\text { e aguarda o desembaraço da DI. Logo após a parametrização e desembaraço, o despachante } \\
\text { encaminha para o setor fiscal DI, CI, ICMS e o arquivo XML, aguarda a emissão da Nota Fiscal } \\
\text { do Estaleiro para iniciar com a coleta da carga no porto de desembaraço. }\end{array}$ \\
\hline FISCAL & $\begin{array}{l}\text { Efetuar a emissão da Nota Fiscal de entrada assim que receber do Despachante o } \\
\text { Comprovante de Importação e o arquivo XML para entrada do material. Assim que emitida a NF, } \\
\text { é encaminhada para o Despachante realizar a liberação da carga no terminal alfandegário e } \\
\text { transporte até o estaleiro. Após a confirmação da carga pelo Almoxarifado, o setor providencia a } \\
\text { baixa da NF no sistema IFS e inicia o processo de conferência entre o arquivo XML da DI com o } \\
\text { sistema de estoque SPMAT. Em conformidade com essas atividades, o setor, então, } \\
\text { providencia o lançamento do arquivo no sistema REPLAT da receita federal. }\end{array}$ \\
\hline ALMOXARIFE & $\begin{array}{l}\text { Receber e conferir a mercadoria pelo setor de Almoxarifado. Este tem a responsabilidade de } \\
\text { conferir a carga recebida com a NF de entrada e, em seguida, faz o lançamento da carga no } \\
\text { sistema da SPMAT e IFS. Estando ok o recebimento, o Almoxarifado informa à Engenharia que } \\
\text { o material está disponível. }\end{array}$ \\
\hline $\begin{array}{l}\text { PLATAFORMA } \\
\text { OBRA }\end{array}$ & $\begin{array}{l}\text { Encerrado o processo de importação com o recebimento da carga no canteiro de Obras, inicia-se } \\
\text { a fase de industrialização e construção da plataforma. }\end{array}$ \\
\hline
\end{tabular}

Fonte: dados da pesquisa.

Para construção do fluxograma conforme os conceitos do BPM, o pesquisador utilizou o aplicativo Bizagi Process Modeler. De forma genérica e com base nas informações do quadro 3 , possibilitou a modelagem conforme apresentado na figura 2.

FIGURA 2 - Fluxo de Processo de Importação

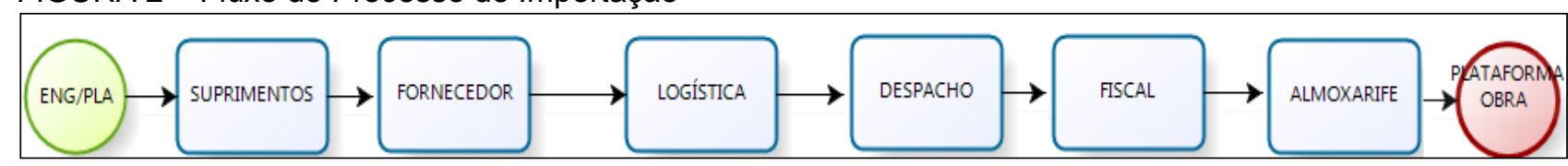

FONTE: dados da pesquisa.

A utilização do fluxograma, por meio do BPM, é uma técnica que possibilita especificar, controlar, executar e analisar processos de importação com mais eficiência. Trata, de forma holística, os processos no sentido organizado e coordenado do fluxo. Com isso, o fluxo oferece ao Despachante uma ferramenta importante na prestação de serviço, com a capacidade de perceber, evitar, eliminar e recuperar as falhas. 
Para isso, elaborou-se o fluxo completo de importação dos materiais e equipamentos do estaleiro, no qual apresenta, na figura 3, o fluxo de materiais e equipamentos com todas as atividades principais e paralelas.

FIGURA 3 - Fluxo de Importação de Materiais e Equipamentos.

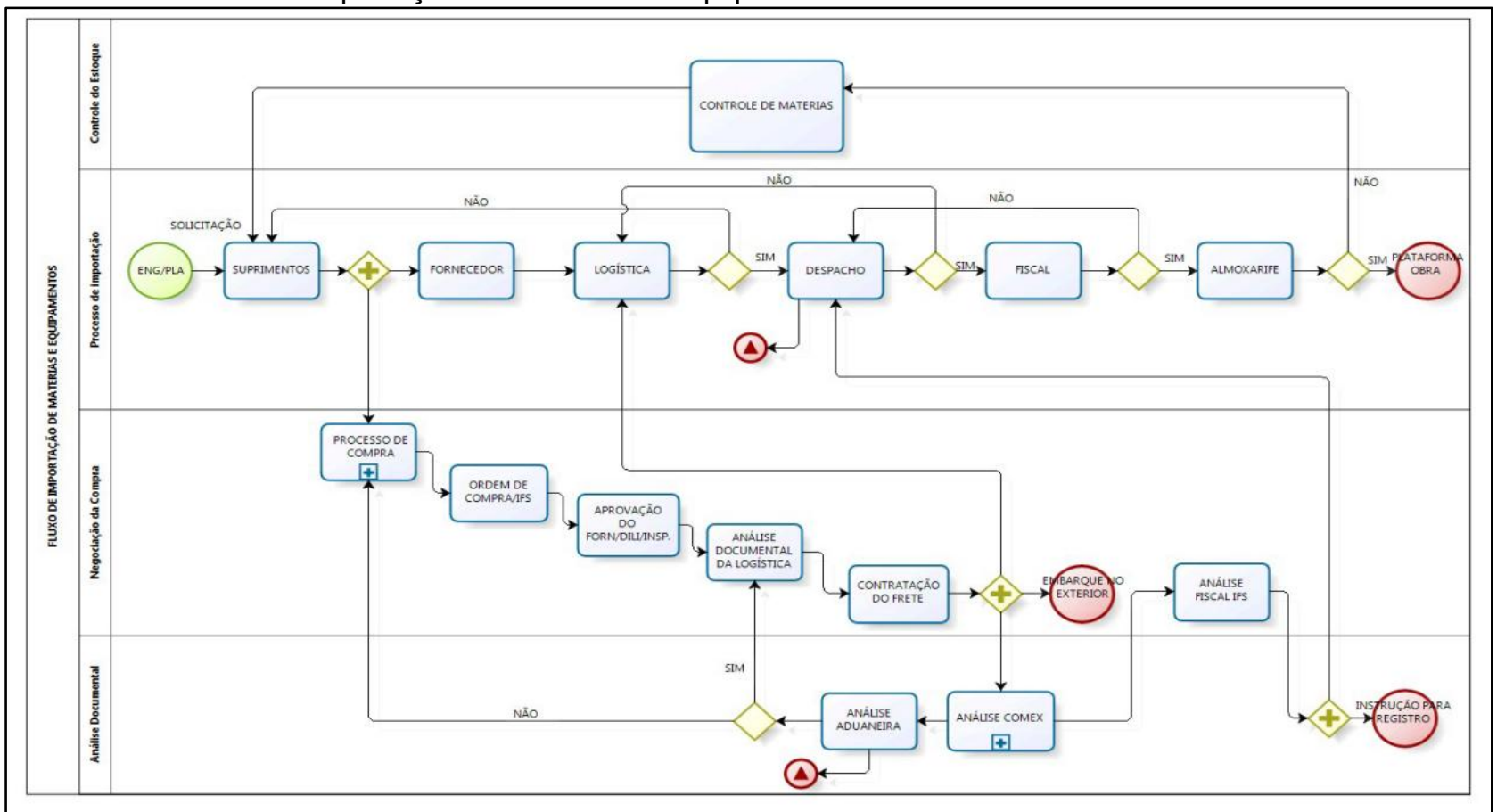

FONTE: dados da pesquisa.

\section{AÇÕES PARA MELHORIA DE PROCEDIMENTOS}

Na figura 4, o fluxo de atividade, nas raias de Negociação de Compra e na Análise documental, é paralelo ao Processo de Importação. A prestadora de serviço atuou, primeiramente, na análise documental, sendo a responsável em analisar as questões aduaneiras que possibilitam ao setor de Logística autorizar o embarque das cargas.

FIGURA 4 - Fluxo de Negociação de Compra e Análise documental

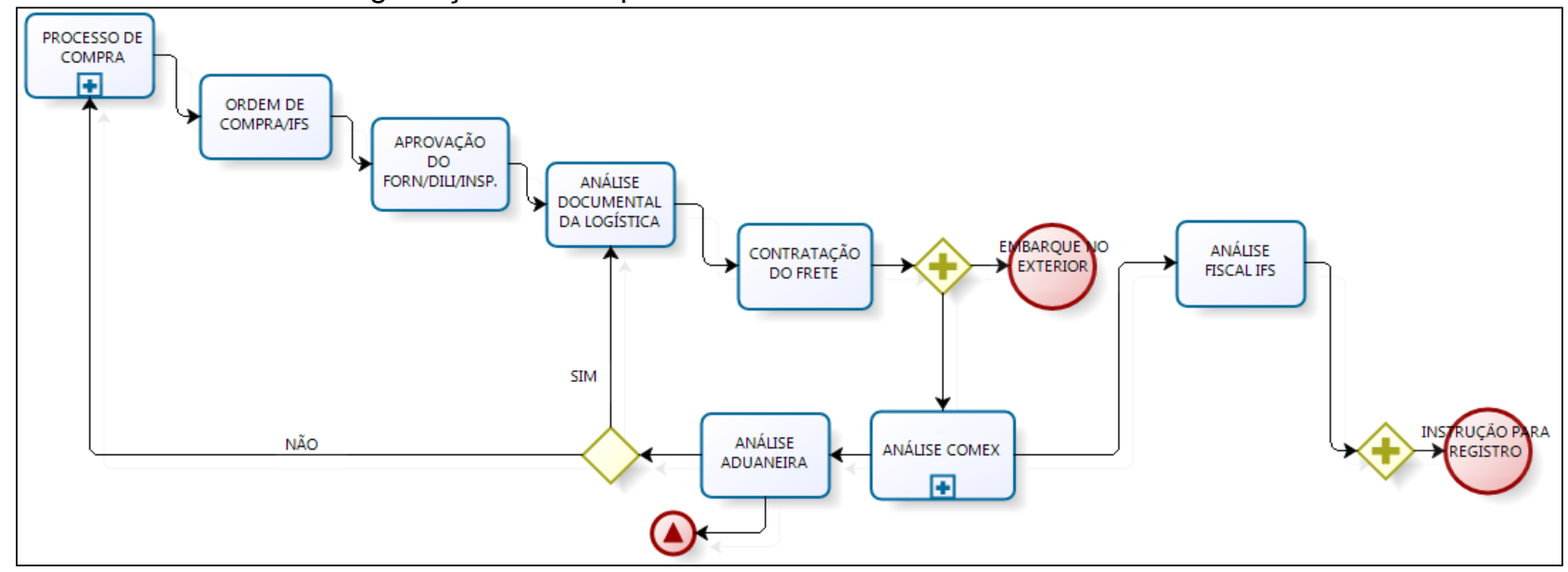

FONTE:dados da pesquisa.

Pode-se localizar, no processo de importação, as falhas da prestadora de serviço, como apontadas pelos atores do trabalho. Elas estão especificamente na notação da Análise Aduaneira, atividade exclusiva do despachante referente às exigências aduaneiras no Brasil e no fluxo, percebido pela notação de Sinal de alerta sobre a falha. (i) Demora na análise da Commercial Invoice; (ii) Excesso de e-mails sobre questionamentos dos produtos importados; (iii) Demora na elaboração da Planilha de Classificação; (iv) Não consultam processos anteriores que entraram com o mesmo material; 
A outra falha está localizada na segunda participação. E a mais importante do despachante dentro do fluxo principal de importação é a atividade de despacho da carga, conforme figura 5.

FIGURA 5 - Fluxo de Importação

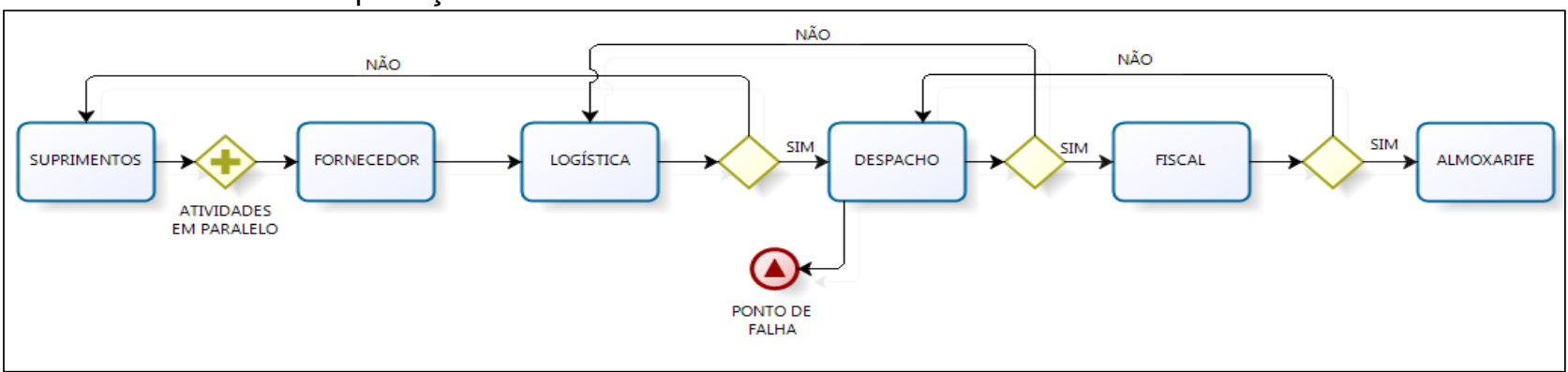

FONTE: dados da pesquisa.

As principais falhas relatadas e analisadas nesse ponto estão relacionadas com o registro da declaração de importação, pois erro com a demora no registro podem acarretar impactos significantes por conta da falta do material no canteiro de obra. (i) Falta de acompanhamento na chegada ao porto de descarga; (ii) Demora no registro da Declaração de Importação - DI; (iii) Falhas na Descrição da DI.

\section{CONSIDERAÇÕES FINAIS}

Inicialmente, cabe considerar que a motivação para a realização deste trabalho surgiu em razão da prestadora de serviços ter algumas dificuldades de eliminar ou evitar as falhas no processo de importação que caracterizam como um problema dentro desse processo. Por isso, o desafio gerencial é justamente de elaborar o fluxo de serviço de importação para eliminar ou solucionar possíveis falhas no processo de prestação de serviços aduaneiros e, com isso, evitar a insatisfação do cliente.

O presente trabalho possibilitou: identificar as falhas no processo de importação através das experiências, seja dos funcionários, seja do próprio pesquisado de mapear o processo de importação do estaleiro para construção de um fluxo de serviço. Identificou-se que existem falhas do fornecedor e do próprio cliente, as quais acarretam erros para a prestadora, porém pode-se perceber que, com a utilização do fluxo, possibilitou-se alinhar as atividades estabelecidas e pertinentes ao processo de importação, tanto com o cliente quanto com o prestador.

Para isso, o pesquisador buscou elementos teóricos para sustentação do trabalho referente às falhas e ao fluxo de serviço no processo de importação. Na literatura, os autores como Lovelock (1995), Johston \& Clark (2014) e Fitzsimmon \& Fitzsimmon (2014) foram pertinentes não só com a identificação de falhas no processo de importação, bem como na prestação de serviço que contribuiu com o entendimento do mapeamento do processo e fluxograma. $\mathrm{Na}$ elaboração do fluxo, foram utilizados conceitos do BPM, embasados pelos autores Benedete (2007), Baldam et al. (2007) e Forster (2005) - os quais possibilitaram construir, através do mapeamento, para melhor executar, monitorar e analisar processos de importação.

Em relação à ferramenta BPM, usada para elaboração do fluxo, destaca-se que essa é gratuita e, assim, pode ser usada por todos aqueles que necessitam elaborar estudos semelhantes. Além disso, este trabalho poderá ser útil em outras pesquisas voltadas a investigar processos de importação, que precisam de ações para identificação de falhas e para melhorar a prestação do serviço e para lidar eficazmente com os problemas do cliente, relacionados com a satisfação e lealdade.

Com relação às dificuldades encontradas na pesquisa, essas foram por conta da diminuição do fluxo de serviços e demissões de funcionários que poderiam contribuir com informações no processo de importação. Outra dificuldade foi durante as entrevistas, todos foram bem colaborativos nas participações, mas o pesquisador pôde notar certa diferença de personalidade ou não abertura das informações.

Portanto, a importância da prestação de serviço está em atender às expectativas do cliente sobre o serviço esperado, de forma eficiente e rápida. Para tanto, é preciso o prestador tomar ações estratégicas e gerenciais de atividades relacionadas diretamente ao cliente. Em suma, é definir a recuperação do serviço como a ação de identificar e lidar com as falhas na prestação de serviço para melhorar o desempenho.

\section{REFERÊNCIAS}

ABIB, G., HOPPEN, N.; HAYASH JUNIOR, P. Observação participante em estudos de administração da informação no Brasil. RAE-Revista de Administração de Empresas, v. 53, n. 6, p. 604-616, 2013.

BARROS, M. D.; OLIVEIRA, A. S. Uma adaptação do modelo SERVQUAL para avaliação e classificação de qualidade em serviços de um restaurante ala carte. In X Congresso Nacional de Excelência em Gestão, 10, 2014, Rio de Janeiro. Anais eletrônicos. Rio de Janeiro, 2014.p. 1-16. 
BENEDETE JUNIOR, A. C. Roteiro para a definição de uma arquitetura SOA utilizando BPM. $2007.68 \mathrm{f}$. Monografia (MBA em tecnologia da informação) - Programa de Educação Continuada em Engenharia, Universidade de São Paulo, São Paulo, 2007.

CERTO, S. C. Modern Management: diversity, quality, ethics, and the global environment. Boston, MA.: Allyn and Bacon, 1994.

CHEUNG, Y.; BAL, J.Process analysis techniques and tools for business improvements.Business Process Management Journal, v. 4, n.4, p. 274-290, 1998.

CRESWELL, J. W. Projeto de Pesquisa: métodos qualitativo, quantitativo e misto. 2. ed. São Paulo: Artmed, 2007.

CRESWELL, J. W. Investigação qualitativa e projeto de pesquisa: escolhendo entre cinco abordagens. 3. ed. Porto Alegre: Penso, 2014.

FITZSIMMONS, J. A.; FITZSIMMONS, M. J. Administração de Serviços: Operações, Estratégia e Tecnologia da Informação. Porto Alegre: Amgh, 2014.

FLICK, U. Desenho da pesquisa qualitativa. Porto Alegre: Artmed, 2009.

FLYVBJERG, B. Five misunderstandings about case-study research. Qualitativeinquiry, v. 12, n. 2, p. 219-245, 2006.

GIL, A. C. Como elaborar projetos de pesquisa. 4. ed. São Paulo: Atlas, 2002.

GIL, A. C. Métodos e técnicas de pesquisa social. 6. ed. São Paulo: Atlas, 2008.

GO, M.; KIM, I. In-flight NCCI management by combining the Kano model with the service blueprint: A comparison of frequent and infrequent flyers. Tourism Management, v. 69, n. 1, p. 471-486, 2018.

HE, Z.; AGGARWAL, V.; NOF, S. Y. Differentiated service policy in smart warehouse automation. International Journal of Production Research, v. 56, n. 22, p. 6956-6970, 2018.

JOHNSTON, R.; CLARK, G. Administração de operações de serviços. São Paulo: Atlas, 2014.

LONGARAY, A. A.; PEREIRA JR., E. F. Z.; MUNHOZ, P. R.; TONDOLO, V. G. Proposals for redesigning processes and the role of organizational teams: an analysis of scientific production in the light of bibliometrics. Sistemas \& Gestão, v. 13, n. 2, p. 246-25, 2018.

LOVELOCK, C. H. Product plus: produto+serviço. Nova York: Makron Books, 1993.

MARTINS, G. D. A.; THEÓPHILO, C. R. Metodologia da Investigação Científica para Ciências Sociais Aplicadas. São Paulo: Atlas, 2009

MENEGON, V. M. Por que jogar conversa fora? Pesquisando no cotidiano. p. 215-242; In: SPINK, M. J. (org.) Práticas Discursivas e Produção de Sentidos no Cotidiano: Apresentações Teóricas e Metodológicas. 2ª ed., São Paulo: Cortez, 2000.

MORENO, V.; SANTOS, L. H. A. Gestão do conhecimento e redesenho de processos de negócio: proposta de uma metodologia integrada, Perspect. Ciênc. Inf., v.17, n.1, p.203-30, 2012.

NETTO, F. S. Gerenciamento de Processos de Negócio: um estudo teórico-comparativo sob as óticas da Gestão Empresarial e da Tecnologia da Informação. In: V Simpósio de Excelência em Gestão e Tecnologia, 5., 2008, Rio de Janeiro. Anais eletrônicos. Rio de Janeiro, 2008. p. 1-15.

PEREIRA JUNIOR, E. F. Z; LONGARAY, A. A.; MUNHOZ; P. R. S. Propostas de redesenho de processos e o papel das equipes organizacionais: uma análise da produção científica à luz da bibliometria. In: XXVIII Encontro Nacional de Cursos de Graduação em Administração, 28, 2017, Brasília. Anais eletrônicos. Brasília, 2017. p. 1-18.

PEREIRA JUNIOR, E. F. Z.; LONGARAY, A. A.; SILVA, J. C. D.; FLORES, J. F. Mapeamento de processos e equipes organizacionais: um estudo de caso na Secretaria de Educação à Distância da Universidade Federal de Rio Grande FURG. in: XXIX Encontro Nacional de Cursos de Graduação em Administração, 29., 2018, São Paulo. Anais eletrônicos. São Paulo, 2018. p. 1-18.

PINHO, A. D.; LEAL, F.; ALMEIDA, D. D. A Integração entre o Mapeamento de Processo e o Mapeamento de Falhas: dois casos de aplicação no setor elétrico. In: XXVI Encontro Nacional de Engenharia de Produção, 27, 2006, Fortaleza. Anais eletrônicos. Fortaleza, 2006. p. 1-9.

ROESCH, S. M.; BECKER, G. V.; de MELLO, M. I. Projetos de estágio e de pesquisa em administração: guia para estágios, trabalhos de conclusão, dissertações e estudos de caso. São Paulo: Atlas, 2015.

SANTANA, L. da S.; BORGES, F. A. S.; BORGES, F. G. Aplicação do service blueprint como ferramenta de análise e mapeamento de processos em serviços, um estudo de caso em uma concessionária de máquinas pesadas. in XXXI Encontro Nacional de Engenharia de Produção, 31., 2011,Belo Horizonte. Anais eletrônicos. Belo Horizonte, 2011. p. 1-12.

SEVERINO, A. J. Metodologia do trabalho científico. 2. ed. São Paulo: Cortez, 2017.

SZEITHAML, V. A.; BERRY, L.; PARASURAMAN, A. A excelência em serviços: como superar as expectativas e garantir a satisfação completa de seus clientes. 1. ed. São Paulo: Saraiva, 2014.

SOUZA, A da S. Sobre a construção da insatisfação: reflexões críticas sobre o discurso do marketing. Tese (Doutorado em Engenharia de Produção) - Programa de Pós-Graduação em Engenharia de Produção. Universidade Federal de Santa Catarina. Florianópolis: UFSC, 2005. 
VILLAMIZAR, L. A. R.; RAMIREZ, N. A.; RODRIGUEZ, M. R. Evaluacióndeldesempeño de servicios de Atención Primaria em Salud: experiencia em municípios ruralesen Santander, Colombia. Revista de Salud Pública, v. 15, n. 1, p. 183-195, 2013.

YIN, R. K. Estudo de Caso: Planejamento e métodos. 5. ed. Porto Alegre: Bookman, 2015.

ZACHARIAS, M. L. B.; FIGUEIREDO, K. F.; de ALMEIDA, V. M. C. Determinantes da satisfação dos clientes com serviços bancários. RAE-eletrônica, v. 7, n. 2, p. 1-23, 2008. 